\title{
Rhox13 is required for a quantitatively normal first wave of spermatogenesis in mice
}

\author{
Jonathan T Busada ${ }^{1, \dagger}$, Ellen K Velte ${ }^{1}$, Nicholas Serra ${ }^{1}$, Kenneth Cook ${ }^{1}$, Bryan A Niedenberger ${ }^{1}$, \\ William D Willis², Eugenia H Goulding², Edward M Eddy² and Christopher B Geyer 1,3,4 \\ ${ }^{1}$ Department of Anatomy and Cell Biology, Brody School of Medicine at East Carolina University, Greenville, North \\ Carolina, USA, ${ }^{2}$ Gamete Biology Group, Reproductive and Developmental Biology Laboratory, National Institute of \\ Environmental Health Sciences, National Institutes of Health, Research Triangle Park, North Carolina, USA, \\ ${ }^{3}$ East Carolina Diabetes and Obesity Institute, and ${ }^{4}$ Brody School of Medicine at East Carolina University, \\ Greenville, North Carolina, USA
}

Correspondence should be addressed to C B Geyer; Email: geyerc@ecu.edu

${ }^{\dagger}(\mathrm{J} T$ Busada is now at Molecular Endocrinology Group in the Signal Transduction Laboratory, National Institute of Environmental Health Sciences, Research Triangle Park, North Carolina, USA)

\begin{abstract}
We previously described a novel germ cell-specific X-linked reproductive homeobox gene (Rhox13) that is upregulated at the level of translation in response to retinoic acid (RA) in differentiating spermatogonia and preleptotene spermatocytes. We hypothesize that RHOX13 plays an essential role in male germ cell differentiation, and have tested this by creating a Rhox13 gene knockout (KO) mouse. Rhox13 KO mice are born in expected Mendelian ratios, and adults have slightly reduced testis weights, yet a full complement of spermatogenic cell types. Young KO mice (at $\sim 7-8$ weeks of age) have a $\approx 50 \%$ reduction in epididymal sperm counts, but numbers increased to WT levels as the mice reach $\sim 17$ weeks of age. Histological analysis of testes from juvenile KO mice reveals a number of defects during the first wave of spermatogenesis. These include increased apoptosis, delayed appearance of round spermatids and disruption of the precise stage-specific association of germ cells within the seminiferous tubules. Breeding studies reveal that both young and aged KO males produce normal-sized litters. Taken together, our results indicate that RHOX13 is not essential for mouse fertility in a controlled laboratory setting, but that it is required for optimal development of differentiating germ cells and progression of the first wave of spermatogenesis.

Reproduction (2016) 152 379-388
\end{abstract}

\section{Introduction}

Spermatogenesis begins in the neonatal mouse testis with the transition of quiescent prospermatogonia into stem, progenitor and differentiating type A spermatogonia (Yoshida et al. 2006, Drumond et al. 2011, Yang \& Oatley 2014, Niedenberger et al. 2015, Busada \& Geyer 2016). These three types of spermatogonia provide the foundation for the 'first wave of spermatogenesis' that occurs during the first $\sim 6$ weeks of postnatal life, and after that, the spermatogonial stem cells (SSCs) supply subsequent waves during steady-state spermatogenesis. SSCs divide asymmetrically to either produce another SSC (self-renewal) or an undifferentiated progenitor spermatogonium that will proliferate before eventually differentiating in response to retinoic acid (RA) (Yang \& Oatley 2014, Busada \& Geyer 2016). Differentiating type $A$ spermatogonia will then proceed through six divisions $\left(A_{1}, A_{2}, A_{3}, A_{4}, \ln , B\right)$ before entering prophase I of meiosis as preleptotene spermatocytes. Following meiosis, haploid round spermatids undergo a dramatic morphological transformation during the process of spermiogenesis that culminates in the release of testicular sperm into the lumina of the seminiferous tubules.

The first cohort of differentiating spermatogonia proceed through these above-mentioned steps with remarkable precision during the first 5 weeks of life in mice such that specific advanced germ cell types appear in the testis in consistent numbers on particular days of postnatal development (Bellve et al. 1977), with minor strain variation. For example, in testes of $\mathrm{C} 57 \mathrm{BL} / 6$ mice, these germ cell types first appear on the following postnatal $(\mathrm{P})$ days: preleptotene spermatocytes $=\mathrm{P} 8$, leptotene spermatocytes $=\mathrm{P} 10, \quad$ zygotene spermatocytes $=\mathrm{P} 12$, pachytene spermatocytes $=\mathrm{P} 14$, round spermatids $=\mathrm{P} 20$ and testicular sperm $\approx \mathrm{P} 35$. The first wave of spermatogenesis results in the appearance of functional sperm in the epididymis by 6 weeks of age in mice, which ensures 
their reproductive competence at an early age. It also provides researchers with an excellent model system for studying spermatogenesis, as relatively pure populations of specific germ cell types can be isolated for study, and perturbations in germ cell development are readily identified.

The 'reproductive homeobox $\underline{X}$-linked,' or Rhox, genes are located on the $X$ chromosome in mammals and encode homeodomain-containing transcription factors. The Rhox genes are expressed primarily in reproductive tissues including the testis, ovary, epididymis and placenta (Geserick et al. 2002, Wayne et al. 2002, Maclean et al. 2005, MacLean \& Wilkinson 2010, Song et al. 2013). Their expression is regulated, at least in part, at the level of transcription by DNA methylation (Jackson-Grusby et al. 2001, Oda et al. 2006, Maclean et al. 2011, Richardson et al. 2014). The genomes of multiple mammals contain Rhox genes that are located on a syntenic region on the $\mathrm{X}$ chromosome and are likely expressed in reproductive tissues (Maclean et al. 2005, Wang \& Zhang 2006, Song et al. 2013, Wilming et al. 2015). There are only three genes in humans (RHOXF1, RHOXF2 and RHOXF2B), and there is evidence that these genes are rapidly evolving in primates (Niu et al. 2011). In mice, an evolutionary expansion generated a collinear cluster of 33 Rhox genes discovered in 2005 by the Wilkinson Laboratory (Maclean et al. 2005). The cluster contains 13 unique Rhox genes (named Rhox 1 13), as well as multiple duplicated copies of Rhox 2-4 (MacLean et al. 2006). A few of the Rhox genes have been targeted in mice by knockout (KO) or RNAi (KD) approaches to determine their roles in fertility. Inactivation of the Sertoli-expressed Rhox 5 (by gene $\mathrm{KO}$ ) and Rhox8 (by siRNA KD) resulted in male subfertility, with increased germ cell apoptosis, reduced cauda epididymal sperm counts and impaired sperm motility (Maclean et al. 2005, Welborn et al. 2015).

After the initial reports of the Rhox gene cluster (in which 12 unique genes were described), we discovered another gene just downstream of Rhox 12 that we designated Rhox13 that is only expressed in male and female germ cells (Geyer \& Eddy 2008). In the female, Rhox13 mRNA is present in the fetal ovary, with RHOX13 protein detectable in oogonia and preleptotene oocytes (Geyer \& Eddy 2008). Based on the coincidence of mRNA and protein solely in the fetal ovary, we concluded that Rhox 13 expression is under transcriptional control in female germ cells. On the contrary, Rhox $13 \mathrm{mRNA}$ is present in all stages of testis development from embryonic day (E) 12.5 through adulthood, including in pachytene spermatocytes and round spermatids ( $\mathrm{T}$ Busada, E K Velte, N Serra, K Cook, B A Niedenberger, W D Willis, E H Goulding, E M Eddy and C B Geyer, unpublished observations). However, RHOX13 protein is only readily detectable in spermatogonia and preleptotene spermatocytes. We found that Rhox 13 mRNAs are repressed in prospermatogonia through a direct interaction with the RNA binding protein NANOS2, and this repression is apparently alleviated in response to RA (Geyer et al. 2012, Chappell et al. 2013). This translational control in the testis results in a protein expression pattern for RHOX13 that is remarkably similar to that in the female (oogonia/spermatogonia and preleptotene oocytes/ spermatocytes), although they seem to be determined by distinct mechanisms. Therefore, we hypothesize that RHOX13 plays an essential role in germ cell differentiation in both sexes before meiotic initiation.

In this report, we examine the requirement for RHOX13 in male germ cell development by generating Rhox 13 $\mathrm{KO}$ mice and analyzing their reproductive phenotype. Testes of Rhox $13^{-/ y}$ males exhibit delayed appearance of germ cell types and a significant increase in germ cell apoptosis during the first wave of spermatogenesis, which results in reduced numbers of epididymal sperm in young adult males. These defects are not seen in subsequent waves of spermatogenesis, as Rhox $13^{-/ y}$ males age and their fertility are not significantly altered, at least in a controlled laboratory setting. Altogether, our results indicate that RHOX13 is required for a quantitatively normal first wave of spermatogenesis in the mouse.

\section{Materials and methods}

\section{Animal care}

All animal procedures were performed in accordance with the National Research Council Guide for the Care and Use of Laboratory Animals and approved by the Animal Care and Use Committees of East Carolina University (AUP \#A181) and the National Institute of Environmental Health Sciences. C57BL/6NCrl mice were obtained from Charles River Laboratories, Inc (Raleigh, NC, USA). Neonatal and juvenile mice up to P12 were euthanized by decapitation, and mice older than $\mathrm{P} 12$ were killed by $\mathrm{CO}_{2}$ asphyxiation followed by cervical dislocation.

\section{Generation of Rhox13 KO mice}

The mouse Rhox13 gene (MGl:1920864) was targeted in E14Tg2a.4 (129/Ola) mouse embryonic stem (ES) cells derived from male embryos (BayGenomics, MMRRC-015890) using homologous recombination. The Rhox $13^{\text {tm1a(KOMP)Wtsi }}$ vector, (CDS79660), a preconditional 'knockout first' vector containing loxP and FRT sites, was obtained from the KOMP repository (www.komp.org/geneinfo.php?geneid=3451). The vector was linearized and electroporated into ES cells grown and selected as described previously (Cho et al. 2001). Recombinant clones that correctly incorporated the Rhox 13 targeting construct into the $\mathrm{X}$ chromosome were identified by PCR and Southern blot analysis. One correctly targeted ES cell clone was electroporated with the circular pCAGGS-FLPe-IRES Spuro construct (Gene Bridges SSRF001) to excise the sequence flanked by FRT sequences, and then recloned. The resulting clones were rescreened to verify excision of the FRT-flanked regions and selected subclones were injected into $\mathrm{C} 57 \mathrm{BL} / 6 \mathrm{~N}$ 
blastocysts to create chimeras. Male chimeras were bred to female $\mathrm{C} 57 \mathrm{BI} / 6 \mathrm{~N}$ mice, and pups were screened by coat color and genotyping to confirm germline transmission. Because only female pups carrying the mutant allele were produced (since Rhox13 is X-linked), some were used to establish a colony of mice carrying the deleted Rhox 13 allele and others were mated to mice dizygous for the FLP deleter allele (B6. Cg-Tg (ACTFLPe) 9205 Dym/J, JAX Stock No: 005703). Resulting offspring with the FRT-flanked region deleted were mated with Hspa2-Cre mice (Inselman et al. 2010) to produce mice with exon 2 of Rhox 13 deleted (Rhox $13^{-/ y}$ males and Rhox $13^{-/ x}$ females). The colony was maintained by mating Rhox $13^{-/ y}$ males with $\mathrm{C} 57 \mathrm{Bl} / 6 \mathrm{~N}$ females.

\section{PCR genotyping}

The genotypes of Rhox 13 WT and KO mice were determined using PCR to amplify genomic DNA isolated from tail tip tissue. The WT or deleted alleles were amplified using forward (5'-AGGGTTCTCCTAGGGTTGAGACC) and reverse (5'-TCCCTGGAAATGTCCAGAGCAG) primers. Amplification of DNA from wild-type and KO mice should yield single 915 and 267 nt bands when run on a 1.5\% agarose gel.

\section{Breeding studies}

We performed both long-term and short-term breeding studies. For the long-term breeding study, WT and KO male mice aged $\geq$ P60 were paired with a single WT C57BL/6N female. Mice were paired for 92 days, and then males were killed. Female mice were monitored for another 22 days for the appearance of any final litters. For the short-term breeding study, P35 WT males and $\mathrm{KO}$ littermates were paired separately with a single female WT $\mathrm{C} 57 \mathrm{BL} / 6 \mathrm{~N}$ female for 15 days. Male mice were killed at P50, and reproductive parameters analyzed. Female breeders continued to be monitored for 22 more days for the appearance of any final litters.

\section{Cell quantitation from testis sections}

Identification of preleptotene spermatocytes, zygotene spermatocytes and round spermatids was performed during the first wave of spermatogenesis based on characteristic differences in position within the seminiferous cords and tubules, nuclear diameter and chromatin appearance (Bellve et al. 1977). Paraffin sections from Bouin's-fixed testes isolated from P8, P12 and P20 mice were stained with hematoxylin and eosin using standard methods. Male germ cells were manually counted from photomicrographs captured with an Axio Observer A1 microscope (Carl Zeiss Microscopy GmbH, Jena, Germany) equipped with an XL16C digital camera and Exponent version 1.3 software (Dage-MTI, Michigan City, IN, USA). Photomicrographs were analyzed using Zeiss AxioVision software. Seminiferous cords were outlined manually, and the total germ cell numbers were divided by total seminiferous cord surface area and multiplied by 1000 to obtain cells $/ \mathrm{mm}^{2}$. Cell counting was performed on $\sim 30$ round seminiferous cords or tubules in duplicate on testes from at least four different animals.

\section{Cauda epididymal sperm counts}

Sperm obtained from one cauda epididymis were counted in duplicate from each mouse. The cauda epididymides were removed from each mouse immediately after killing and placed into $1 \mathrm{~mL}$ of $1 \mathrm{X}$ PBS at room temperature. Each epididymis was cut into small pieces and gently mixed by repeated passage through a P1000 pipette tip. The solution was diluted with distilled water to immobilize the sperm, and counts were obtained using a hemocytometer.

\section{Daily sperm production counts}

Whole testes were weighed and snap-frozen in liquid nitrogen. A portion of the frozen testis was cut off, weighed, detunicated and homogenized in $1 \mathrm{~mL}$ of lysis solution $(0.9 \% \mathrm{NaCl}$ and $0.05 \%$ Triton X-100). The solution was further homogenized by multiple passages through a 26-gauge needle. The solution was then diluted and the numbers of step 14-16 spermatid heads were counted. The total number of spermatid heads was multiplied by the dilution and then by 2500 and then divided by the weight of the testis fragment, multiplied by the weight of the whole testis and divided by 4.84 to calculate daily sperm production per testis (Robb et al. 1978, Joyce et al. 1993, Ashby et al. 1999).

\section{Immunohistochemistry (IHC) and indirect immunofluorescence (IIF)}

IHC was performed as described previously (Geyer et al. 2012). Briefly, Bouin's-fixed testis sections were deparaffinized and then RHOX13 antiserum (generated previously, (Geyer \& Eddy 2008)) was applied at 1:500 for $1 \mathrm{~h}$ at room temperature without antigen retrieval. Primary antibody was omitted as a negative control. Detection was performed using a VECTASTAIN ABC kit (Vector Laboratories, Burlingame, CA, USA), and sections were counterstained with hematoxylin. Images were captured as described above. IIF was performed as before (Busada et al. 2014, Niedenberger et al. 2015, Busada et al. 2015a,b). Briefly, 4\% PFA-fixed and O.C.T.-embedded $5 \mu \mathrm{m}$ frozen sections were incubated in blocking buffer for $30 \mathrm{~min}$ at room temperature and then incubated in primary antibody for $1 \mathrm{~h}$ at room temperature. Primary antibodies were against RHOX13 (1:500, (Geyer \& Eddy 2008)), cleaved poly(ADP-ribose) polymerase 1 (PARP1, 1:100, \#9544 Cell Signaling Technology), BrdU (1:50, \#B35130 Thermo Fisher Scientific) and STRA8 (1:3000, \#ab49602 Abcam). Following stringency washes, sections were incubated in secondary antibody (1:1000 Alexa Fluor-488 donkey antirabbit or donkey anti-goat IgG, Invitrogen) plus phalloidin (1:500, Invitrogen) for $1 \mathrm{~h}$ at room temperature. Blocking and antibody incubations were done in $1 \mathrm{X}$ PBS containing $3 \% \mathrm{BSA}+0.1 \%$ Triton $\mathrm{X}-100$, and stringency washes were done with $1 \mathrm{X}$ PBS $+0.1 \%$ Triton X-100. Primary antibodies were omitted as negative controls. Coverslips were mounted with VECTASTAIN containing DAPI (Vector Laboratories), and images obtained using a FluoView FV1000 confocal laser scanning microscope (Olympus). 


\section{Statistics}

Statistical analyses were performed using Student's $t$-test, and the level of significance was set at $P<0.05$.

\section{Results \\ Generation of the disrupted Rhox13 allele}

The germ cell-expressed X-linked Rhox 13 gene has a rather unique expression pattern. In the male, it is transcribed solely in germ cells throughout testis development, and mRNAs are detectable from E12.5 through adulthood (Geyer \& Eddy 2008, Geyer et al. 2012). However, RHOX13 protein is only readily detectable in spermatogonia and preleptotene spermatocytes, is decreased dramatically in leptotene spermatocytes and is undetectable in pachytene spermatocytes and spermatids (despite both cell types containing abundant Rhox 13 mRNA) (Geyer \& Eddy 2008, Geyer et al. 2012). To test the hypothesis that RHOX13 plays an essential role in male germ cell development, we took a reverse genetics approach to disrupt the Rhox 13 gene. We introduced loxp sites flanking the second exon of the Rhox 13 gene, which encodes a portion of the homeodomain. Since Rhox 13 is only expressed in germ cells, we decided to convert the floxed allele into a deleted allele. This was accomplished by breeding Rhox $13^{\mathrm{fl} /}$ fl female and Rhox $13^{+/ y}$;Hspa2-Cre male mice, which express Cre recombinase in spermatocytes (Inselman et al. 2010). We successfully deleted the floxed allele, and therefore one half of all resultant male pups are $R h o x 13^{-/ y}(\mathrm{KO})$ and the other half are Rhox $13^{+/ y}$ $(\mathrm{WT})$, and we distinguished between them by PCR genotyping (Fig. 1A and B). Deletion of Rhox 13 was confirmed at the protein level by immunostaining, as no RHOX13 was detectable in male germ cells of any of the Rhox13 KO mice (Fig. 1C, E and F).

\section{Analysis of phenotypic traits of Rhox13 KO mice}

Rhox 13 WT and KO mice were generated in equivalent ratios throughout this study. We analyzed males from litters from the first generation after constitutively deleting the Rhox 13 allele and found a relatively high degree of phenotypic heterogeneity both within and between Rhox $13 \mathrm{KO}$ males. Some had extremely low cauda sperm counts and abnormal testis histology, while others had apparently normal testis histology, sperm counts and motility. Most KO mice had a mixture of normal-appearing tubules adjacent to those missing layers of spermatogenic cells, including basal spermatogonia or adluminal spermatocytes and spermatids (Fig. 2A, B, C and D). In addition, there were many vacuolated spaces within the seminiferous epithelia of these $\mathrm{KO}$ tubules, suggesting germ cell loss by apoptosis.
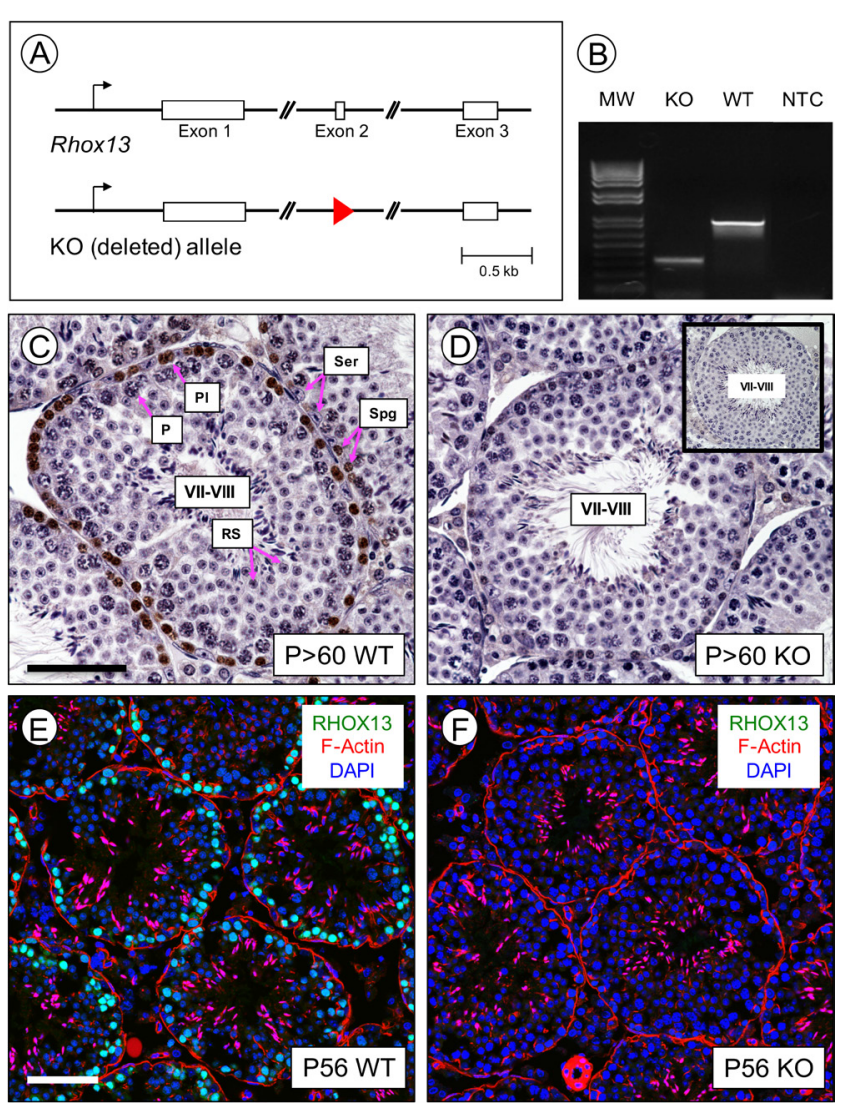

Figure 1 Generation of Rhox 13 KO mice. (A) The Rhox 13 gene comprised three exons (shown in boxes), as is typical of most homeobox genes. We created a $\mathrm{KO}$ allele by deleting exon 2, and a single loxP site remains (red triangle). (B) PCR amplification using primers on either side of exon 2 distinguishes $\mathrm{KO}$ from WT alleles. MW, molecular weight ladder; NTC, no template control. (C and D) IHC was done to verify loss of RHOX13 protein (brown staining) in $P>60$ adult testes. Shown are stages VII-VIII seminiferous tubule sections from WT (C) and KO (D) mice. Sections were counterstained with hematoxylin, and inset (in D) is a no primary antibody control. Spg, spermatogonia; Pl, preleptotene spermatocytes; $\mathrm{P}$, pachytene spermatocytes; RS, round spermatids; Ser, Sertoli cells. (E and F) IIF was done to localize RHOX13 (in green) in WT (E) and KO (F) P56 testes. DNA is stained with DAPI (blue), and F-actin is stained with fluorescently conjugated phalloidin (red). Scale bar $=50 \mu \mathrm{m}$.

To determine whether these histological abnormalities caused differences in reproductive performance, we entered adult $(P>60)$ male WT and KO mice ( $n=4$ for each genotype) into a 5-month breeding study. Males of both genotypes exhibited apparently normal breeding behavior, and we found that there were no statistically significant differences either in the average numbers of pups per litter or in the time taken for birth of the first litter. However, there was a statistically significant increase in the time between litters sired by Rhox $13 \mathrm{KO}$ males when paired with WT females (Fig. 3, $P=0.008$ ).

The Rhox $13 \mathrm{KO}$ mice were produced by injecting 129/Ola ES cells into C57BL/6 blastocysts. Based on the high variability in testis histology and sperm 

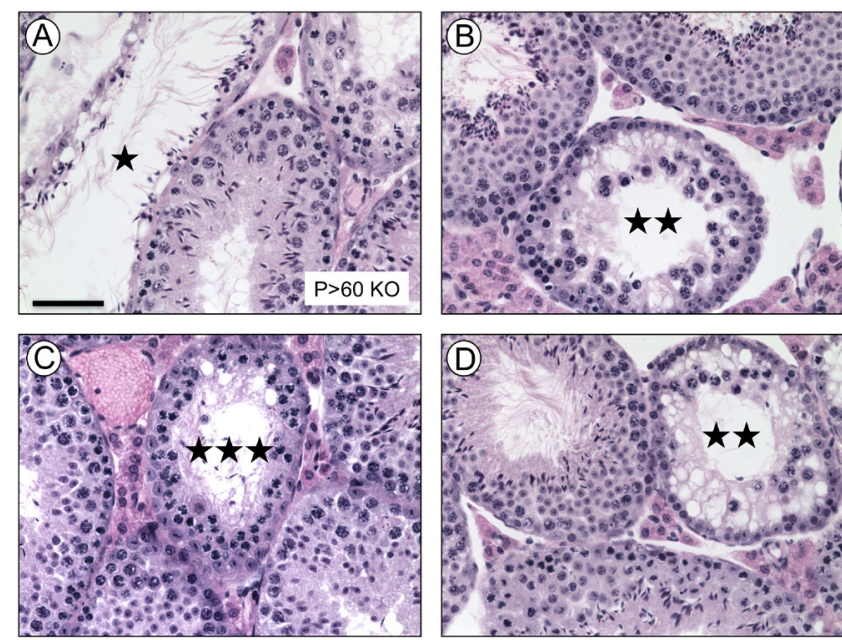

Figure 2 Histological abnormalities of adult $(P>60)$ testes from Rhox $13 \mathrm{KO}$ on a mixed genetic background. (A, B, C and D) Bouin's fixed $\mathrm{KO}$ sections are stained with $\mathrm{H} \& \mathrm{E}$ and abnormal tubules are indicated by asterisks ( $\star=$ only containing condensed spermatids and Sertoli cells; $\star \star=$ lacking spermatids; $\star \star \star=$ lacking spermatids and almost all spermatogonia). Scale bar $=50 \mu \mathrm{m}$.

counts, we chose to backcross the Rhox13 KO line onto the $\mathrm{C} 57 \mathrm{BL} / 6 \mathrm{~N}$ genetic background in order to remove any confounding genetic modifiers and obtain a stable phenotype. Rhox $13^{-/+}$females were bred with WT males for seven generations, and the resulting 'incipient congenic' pups were predicted to have a $>99 \%$ C57BL/6-derived genome. All subsequent analyses were performed using 7 th or later generation mice. Males were killed at P56 (unpaired, or virgin males) and at P50 and P120 (after short-term and longer-term breeding studies) for reproductive phenotypic assessment, and the results are summarized in Table 1 . As expected, there were no differences in body weight at any of the ages examined. Testis weights were $\sim 10-15 \%$ lower in $\mathrm{KO}$ mice at P56 and P120, but this difference did not reach the level of statistical significance. The size and weight of paired seminal vesicles are under androgen control, and therefore differences would suggest differences in testosterone levels (reviewed in Dohle et al. 2003). Although seminal vesicle weights vary considerably between even WT mice, there were no significant differences between genotypes in the three groups of mice. We counted cauda epididymal
A

\begin{tabular}{|c|c|c|}
\hline Genotype & $\begin{array}{c}\text { Average pups } \\
\text { per litter }\end{array}$ & $\begin{array}{c}\text { Days to first } \\
\text { litter }\end{array}$ \\
\hline WT & $7.1 \pm 3.1$ & $24.2 \pm 5.4$ \\
\hline KO & $7.6 \pm 3.1$ & $26.2 \pm 4.7$ \\
\hline
\end{tabular}

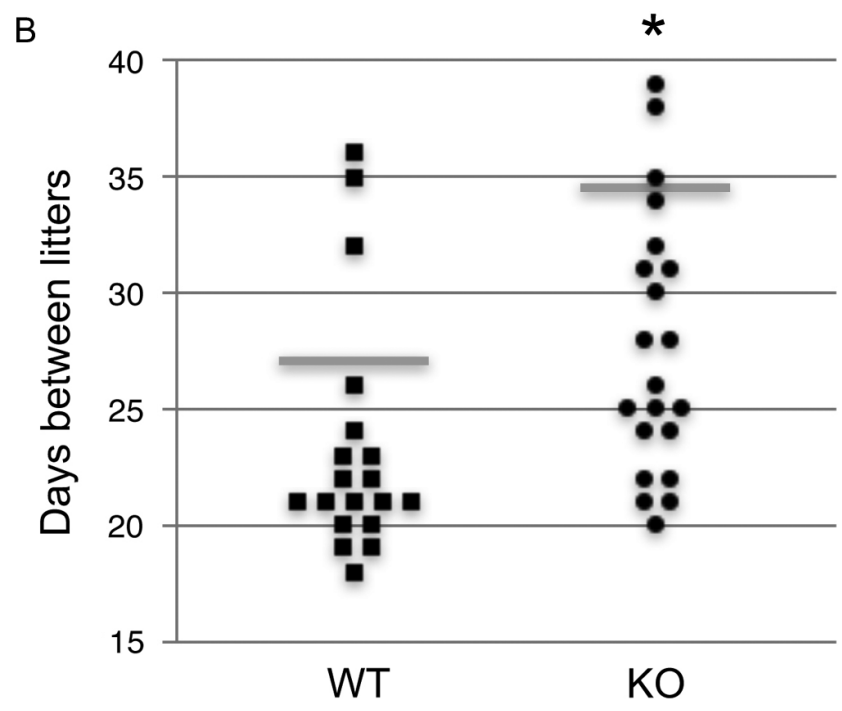

Figure 3 Fecundity results from long-term breeding trial of Rhox13 WT and KO mice on mixed genetic background. (A) The average litter size and days to first litter were not statistically different between Rhox13 WT and KO males. (B) In a graphical representation of time between litters, a horizontal gray line represents the average. Statistical significance is indicated by an asterisk $(P=0.008)$.

sperm from WT and $\mathrm{KO}$ males at P50, P56, and P120 to measure the output of spermatogenesis. These ages are significant because sperm in P50 and P56 epididymides should be products of the first wave of spermatogenesis, while those in P120 epididymides arise from subsequent rounds of adult SSC-derived steady-state spermatogenesis. There were no statistically significant differences in cauda sperm quantity between P120 WT and KO males. On the contrary, young $\mathrm{KO}$ males had reduced numbers of cauda epididymal sperm as compared with WT control littermates at both P56 ( 1.6-fold decrease, $P<0.001)$ and P50 $(\sim 1.5$-fold decrease, not statistically significant). Importantly, P50 males were

Table 1 Reproductive phenotype of backcrossed Rhox13 KO males. All values are presented as averages with standard deviation.

\begin{tabular}{|c|c|c|c|c|}
\hline Genotype (age) & Body weight (g) & Testis weight (mg) & Paired seminal vesicle weight (mg) & Cauda epididymal sperm $\left(\times 10^{6} / \mathrm{mL}\right)$ \\
\hline Rhox13 $3^{+/ y}$ (WT, P50) & $22.4 \pm 0.9$ & $86.4 \pm 2.5$ & $115.4 \pm 12.0$ & $2.5 \pm 1.3$ \\
\hline Rhox13-1y (KO, P50) & $22.0 \pm 1.3$ & $82.5 \pm 2.9$ & $104.3 \pm 35.2$ & $1.7 \pm 0.9$ \\
\hline Rhox13+/y (WT, P56) & $22.4 \pm 0.2$ & $87.5 \pm 0.7$ & ND & $9.41 \pm 0.7^{*}$ \\
\hline Rhox13 $3^{-/ y}(\mathrm{KO}, \mathrm{P} 56)$ & $22.4 \pm 1.3$ & $78.7 \pm 6.3$ & ND & $5.71 \pm 0.6^{*}$ \\
\hline Rhox13 $3^{+/ y}$ (WT, P120) & $32.9 \pm 4.0$ & $100.9 \pm 18.1$ & $296.3 \pm 30.7$ & $12.5 \pm 4.0$ \\
\hline Rhox $13^{-/ y}(\mathrm{KO}, \mathrm{P} 120)$ & $32.4 \pm 1.3$ & $92 \pm 5.3$ & $252.8 \pm 151.8$ & $13.9 \pm 1.9$ \\
\hline
\end{tabular}

$\mathrm{ND}$, not determined. In comparisons of cauda epididymal sperm counts, asterisks indicate statistical differences, at $P<0.001$. $n=3 \mathrm{WT}, 4 \mathrm{KO}$ (P50); $n=2$ WT, 4 KO (P56); $n=4$ WT, 4 KO (P120) WT, 4 KO (P50); $n=2$ WT, 4 KO (P56); $n=4$ WT, 4 KO (P120). 
actively breeding until the day of killing, while P56 males were never paired with females.

\section{Histological abnormalities during the first wave of spermatogenesis}

The reduced sperm counts in younger $\mathrm{KO}$ males (P50 and P56) suggested that the absence of RHOX13 had an effect during the first wave of spermatogenesis. We examined the histology of testes from WT and $\mathrm{KO}$ mice at P8, P12 and P20 because these ages coincide with the appearance of preleptotene spermatocytes, pachytene spermatocytes and round spermatids respectively (Bellve et al. 1977). We found that at P8, there were similar numbers of emergent preleptotene spermatocytes in WT and KO testes (Fig. 4A and B). At P12, there was no difference in the number of leptotene or zygotene spermatocytes (Fig. 4C and D). Round spermatids are the most advanced germ cell type present in the P20 testis, and in WT mice are found adjacent to the lumina of the seminiferous tubules (Bellve et al. 1977). In KO testes, there was a 3.8 -fold reduction in the number of round spermatids per area of seminiferous tubules (Fig. 4E and F), and an apparent difference in the number of tubules containing round spermatids. By P22, both WT and $\mathrm{KO}$ males had similar numbers of round spermatids (data not shown), indicating that this developmental delay was temporary.

\section{Germ cell proliferation is reduced in Rhox13 KO mice during the first wave of spermatogenesis}

The preceding observations suggested an approximate 1 -day delay in the appearance of specific germ cell types in Rhox13 $\mathrm{KO}$ testes during the first wave of spermatogenesis. We assessed whether this might be explained by a change in the extent of germ cell proliferation. We injected juvenile mice with the nucleotide analog 5-bromo-2-deoxyuridine (BrdU), which is only incorporated into DNA of cells that are mitotically active and have passed through $\mathrm{S}$ phase. Mice were killed $20 \mathrm{~h}$ after injection, and testis sections were stained with an antibody recognizing BrdU. We counted BrdU+ proliferating germ cells, and found there were no significant differences in the numbers of BrdU+ germ cells in Rhox13 KO mice at P8 and P20 (Fig. 5).

\section{Rhox13 testes have higher levels of germ cell apoptosis}

We noted an apparent increase in the number of apoptotic-appearing germ cells with pyknotic nuclei and brightly eosinophilic cytoplasm in H\&E-stained Rhox13 KO testis sections during the first wave of
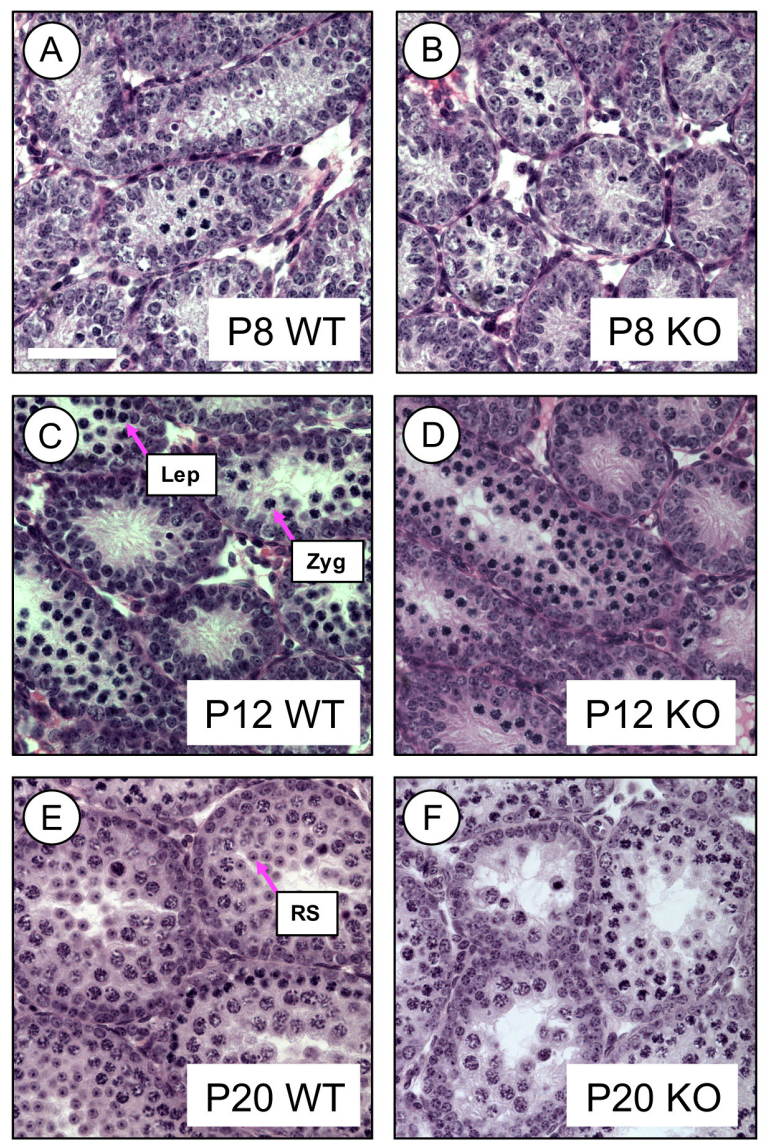

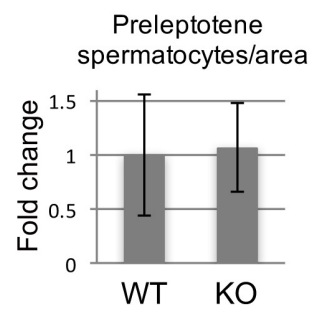

Leptotene+zygotene spermatocytes/area

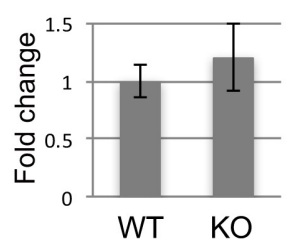

Round spermatids/area

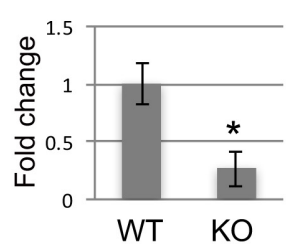

Figure 4 Developmental delays and histological abnormalities during the first wave of spermatogenesis in backcrossed Rhox $13 \mathrm{KO}$ mice. There were no significant differences in the numbers of preleptotene spermatocytes at P8 (A and B) or leptotene (Lep) and zygotene (Zyg) spermatocytes at P12 (C and D). On the contrary, P20 KO testes had significantly reduced numbers of round spermatids (RS) (E and F). Asterisk indicates significance at $P=0.0002$. Scale bar $=50 \mu \mathrm{m}$. 
WT
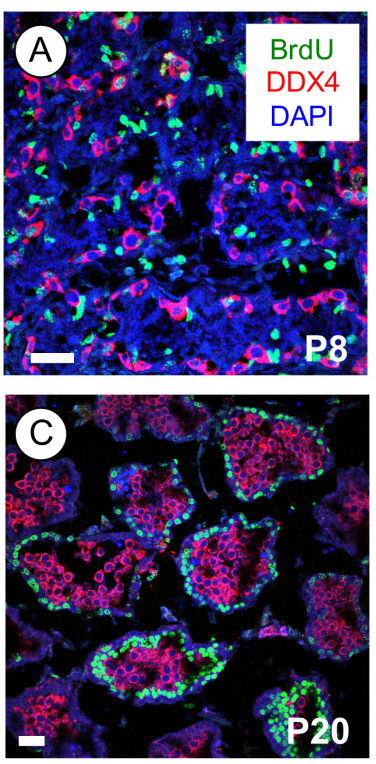

$\mathrm{KO}$
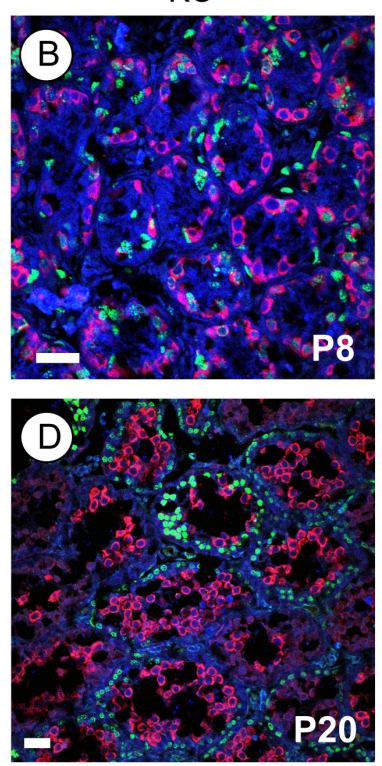

P8

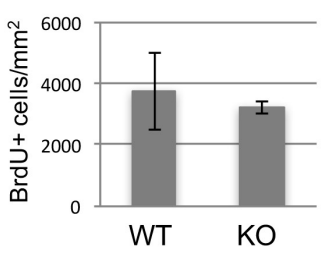

P20

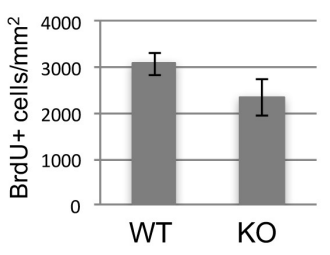

Figure 5 Germ cell proliferation decreases in backcrossed $\mathrm{KO}$ testes during the first wave of spermatogenesis. (A-D) Immunostaining was done to detect BrdU (green) and DDX4 (red), and nuclei were labeled with DAPI (blue) in testes from P8 (A and B) and P20 (C and D) WT (A and C) and $\mathrm{KO}$ (B and D) mice. Ages are indicated on each panel. Scale bars $=30 \mu \mathrm{m}$. spermatogenesis (Fig. 4). To quantify the extent of apoptosis, we stained frozen testis sections with an antibody recognizing cleaved PARP1 (c-PARP1). At P8, there were similar numbers of c-PARP1+ germ cells in WT and $\mathrm{KO}$ testes (Fig. 6A and B). At both P12 and P20, there was a significant increase of approximately three-fold more c-PARP $1+$ germ cells in $\mathrm{KO}$ versus WT testes (Fig. 6C, E and $F, P<0.05$ ). We did not observe significant differences in any of the reproductive parameters measured from P120 adult mice undergoing SSC-derived steady-state spermatogenesis (data not shown).

\section{Breeding studies assess the fertilization ability and efficiency of first wave- and adult SSC-derived sperm}

We could not rule out the possibility that RHOX13 performs an essential role in a process required for fertility that we could not discern from the analyses described previously. To examine this, we performed
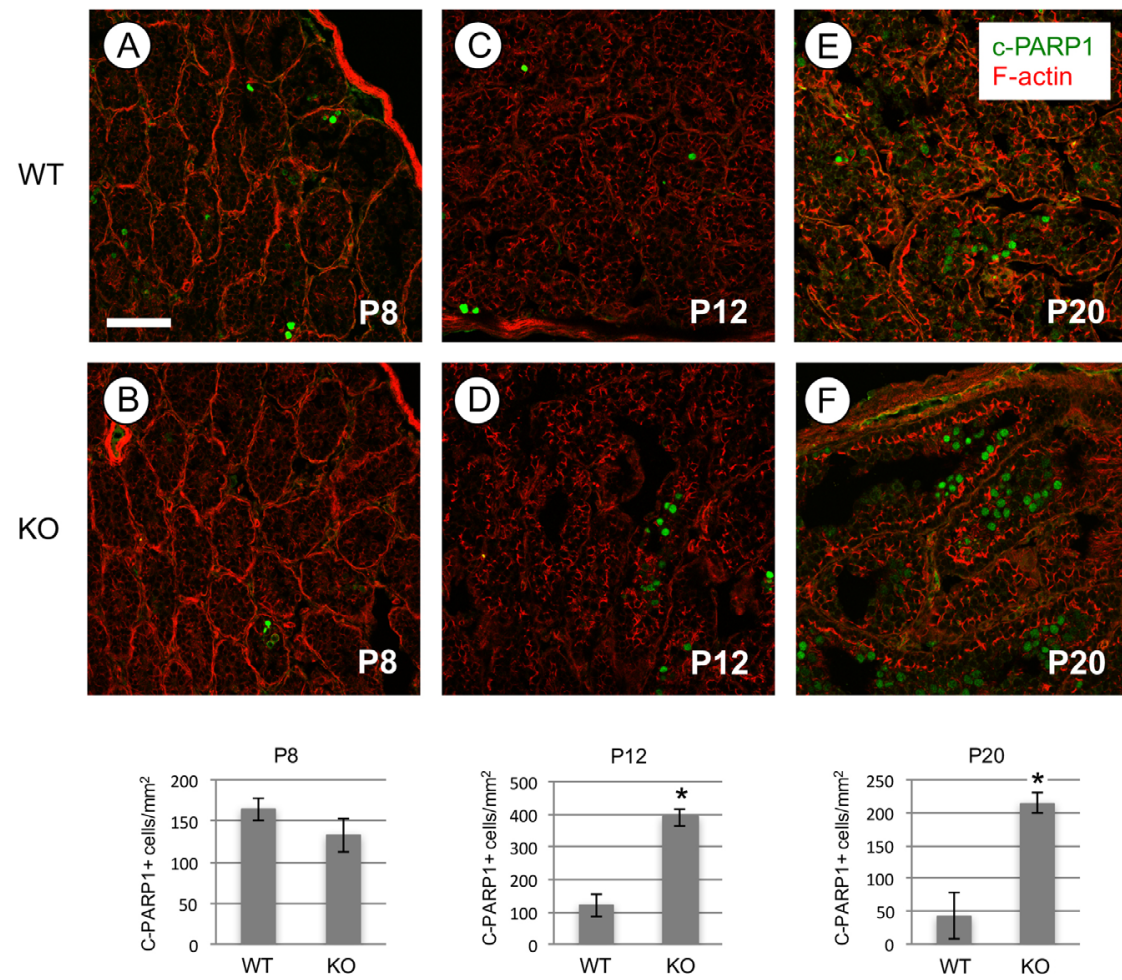
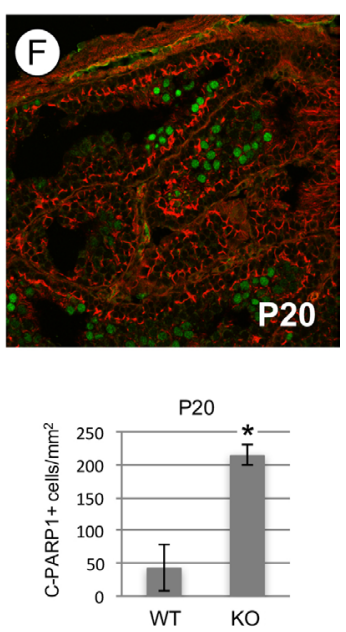

Figure 6 Increased germ cell apoptosis in backcrossed $\mathrm{KO}$ testes during the first wave of spermatogenesis. (A, B, C, D, E and F) Immunostaining was done to detect C-PARP1 (green), and phalloidin-labeled F-actin (red). The c-PARP1+ cells were counted at each age and in each genotype, and the results are presented for each age below their respective panels as c-PARP1+ cells per $\mathrm{mm}^{2}$ of seminiferous cord (P8, P12) or tubule (P20). Asterisk indicates statistical significance $(P<0.05)$. Scale bar $=30 \mu \mathrm{m}$. 
a 5-month breeding trial with four adult males of each genotype (age $=\mathrm{P} 60$ at the beginning of the trial). There were no significant differences in the average time to first litter ( $\mathrm{WT}=22$ days, $K \mathrm{KO}=22$ days), average time between subsequent litters (WT $=25$ days, $K O=20$ days) or average numbers of pups per litter $(\mathrm{WT}=6.75$, $\mathrm{KO}=7.5$ ).

During the first wave of spermatogenesis, $\mathrm{KO}$ testes exhibited a variety of histological abnormalities, decreased proliferation, increased apoptosis and 50\% fewer cauda epididymal sperm. Therefore, we performed a short-term breeding study to assess the fertility of these young male $\mathrm{KO}$ mice. $\mathrm{KO}$ and WT males at P35 were housed with mature females $(P>60)$ for 15 days, and were then killed at P50 $(n=4 \mathrm{KO}, n=3 \mathrm{WT})$. The female mice were monitored for the next 22 days to record any subsequent litters. Two out of the three WT males produced a litter, while two out of four KO males produced a litter. There were no statistically significant differences in average numbers of pups per litter or days to first litter (Table 1). Thus, we conclude that deletion of Rhox 13 does not significantly impair mouse fertility, at least in a controlled laboratory setting.

\section{Discussion}

These studies examined the reproductive phenotype of male Rhox13 KO mice during the first wave of spermatogenesis and during steady-state spermatogenesis in older adult mice. We found that, although RHOX13 is not essential for fertility, its loss led to a number of histological abnormalities and developmental delays that were particularly evident during the first wave of spermatogenesis. Compared with WT littermates, KO testes had delayed appearance of specific germ cell types, histological abnormalities and an approximate three-fold increase in germ cell apoptosis, culminating in a $\sim 50 \%$ reduction in cauda epididymal sperm content in young adult males. These defects were not seen in older adult male mice, indicating a reduced role for RHOX13 in steady-state spermatogenesis.

\section{The effect of genetic background on the reproductive phenotype}

The first Rhox $13 \mathrm{KO}$ mice that we analyzed were on a mixed 129/Ola $\times$ C57BL/6N genetic background. Adult males that we analyzed exhibited a remarkable variety of reproductive phenotypes; some had apparently normal histology and sperm counts, while others had disrupted spermatogenesis. There is precedence in the literature for genetic background effects on fertility phenotypes, and this is likely due to unlinked genetic modifiers. One example is provided from studies of Stra8 KO mice, which exhibited an inconsistent array of spermatogenic defects on a mixed genetic background; the phenotype became consistent once the mutation was backcrossed onto a
C57BL/6N background (Baltus et al. 2006, Anderson et al. 2008). We bred $129 / \mathrm{Ola} \times \mathrm{C} 57 \mathrm{BL} / 6 \mathrm{~N}$ KO mice with WT inbred $\mathrm{C} 57 \mathrm{BL} / 6 \mathrm{~N}$ mice for seven generations to progressively dilute the 129/Ola-derived genome. Based on classical genetics, these 'incipient congenic' mice should have a genetic background that is $>99 \%$ derived from the C57BL/6 strain (Berry \& Linder 2007). These C57BL/6N Rhox 13 males had less of a phenotype than those on the mixed background, suggesting that defects might have been more severe had we chosen to backcross onto the 129/Ola background.

\section{Altered timing and increased apoptosis in Rhox13 KO males during the first wave of spermatogenesis}

We observed a consistent delay in the appearance of round spermatids accompanied by a significant increase in apoptosis beginning at P12. Spermatogenesis in rodents is a tightly coordinated and precisely timed process, and as a consequence, the adult seminiferous tubule segments contain predictable combinations of germ cells in various stages of development. The stage is set for this during the first wave of spermatogenesis, as specific germ cell types appear on defined days of development accompanied by a series of coordinated events such as Sertoli cell terminal differentiation and formation of the blood-testis barrier (BTB). Therefore, it is logical to presume that if the progression of germ cell development were delayed, then the coordination between developing germ cells and their environment would be disrupted. This might contribute to the significant increase in apoptosis during the first wave of spermatogenesis. There are other examples of altered timing of spermatogenesis during the first wave of spermatogenesis. The first is provided by studies of the 'follicle-stimulating hormone $(\mathrm{FSH})$ receptor' $\mathrm{KO}$ mouse, which exhibited decreased testicular weight, reduced seminiferous tubule diameters and a delay in the appearance of spermatids (Krishnamurthy et al. 2001). Another is provided by studies of mice deficient for 'mediator complex subunit 1' (Med1). Med1 KO spermatocytes appeared precociously, approximately 3 days earlier than in WT littermate controls (Huszar et al. 2015). This interesting phenotype included a significant increase in the abundance of pachytene spermatocytes that persisted through at least P42, but did not result in reduced fertility.

The cauda epididymis is the main site for sperm storage in most mammals (Hinton et al. 1996, Moore 1998, Jones 1999, Bedford 2015), and therefore quantifying sperm content provides a reasonable measure of the functional output of spermatogenesis. In young adult males ( P50), we observed a $\sim 50 \%$ reduction in cauda epididymal sperm, the final product of the first wave of spermatogenesis. The fact that virgin males had not expelled any sperm likely explains why there were higher sperm numbers in their cauda epididymides. 


\section{A potential role of Rhox gene cluster in fertility}

Rhox genes are present in all mammalian species examined to date (MacLean \& Wilkinson 2010). There are three Rhox genes in humans (RHOXF1, RHOXF2 and RHOXF2B) (Geserick et al. 2002, Wayne et al. 2002, Song et al. 2013, Richardson et al. 2014), and there are at least eight polymorphic sites (Niu et al. 2011). It will be important to determine whether any polymorphisms are associated with human male infertility. The 33 Rhox genes in mice exhibit unique expression patterns throughout the male and female reproductive systems (Maclean et al. 2005, MacLean et al. 2006, MacLean \& Wilkinson 2010). It is apparent that the individual rodent Rhox genes exhibit a much more restricted expression pattern than the human RHOX genes, which suggests that their encoded proteins may play more refined or specialized roles within various reproductive tissues. In addition, the expansion of the Rhox gene cluster on the $X$ chromosome may contribute to, among other things, the regulation of the first wave of spermatogenesis. Indeed, the defects reported here in Rhox $13 \mathrm{KO}$ mice are most evident during the first wave, and decrease or disappear during steady-state spermatogenesis in the adult testis.

Three other Rhox genes have been disrupted in mice. Rhox9 (previously termed as Gpbox) is expressed in the placenta and in fetal germ cells of both sexes, and targeted disruption did not lead to observable defects in spermatogenesis (Takasaki et al. 2000, 2001). However, it has been proposed that the closely related Rhox 6 gene product could provide functional compensation, as it shares sequence similarity and expression pattern (MacLean \& Wilkinson 2010). Rhox5 and Rhox8 are both expressed selectively in Sertoli cells, and their ablation resulted in male subfertility (Maclean et al. 2005, Welborn et al. 2015). It is likely that RHOX proteins may have overlapping functional roles, which would explain why the reproductive defects reported to date are relatively minor. Future studies in our laboratory will examine the transcriptome-wide changes in gene expression in Rhox13 KO mice in order to identify RHOX13-regulated genes, and it is possible that other Rhox genes are upregulated in the absence of RHOX13 to provide functional compensation in the adult testis.

The first wave of spermatogenesis occurs in rodents, and results in the production of functional sperm capable of fertilization as early as $7-8$ weeks of age in mice. Most rodents become independent by $4-5$ weeks of age and the vast majority are polygamous (Curtis 2010), relying on opportunistic breeding encounters while leading an existence fraught with the danger of being consumed by a wide variety of different predators. Therefore, the ability to successfully reproduce a week or more earlier because of first wave-derived sperm (rather than waiting on germ cell production from SSCs) would increase a male's chances of passing genes to the next generation before a potential early demise. Therefore, the role of the germ cell-expressed Rhox 13 gene may be to support early fertility and increased fecundity by providing additional support for the first wave of spermatogenesis thus favoring the evolutionary expansion of the Rhox gene cluster.

\section{Declaration of interest}

The authors declare that there is no conflict of interest that could be perceived as prejudicing the impartiality of the research reported.

\section{Funding}

This work was supported by a grant from the NIH, National Institute of Child Health and Human Development (HD072552 to $\mathrm{C} \mathrm{B} \mathrm{G)} \mathrm{and} \mathrm{by} \mathrm{the} \mathrm{Intramural} \mathrm{Research} \mathrm{Program} \mathrm{of} \mathrm{the} \mathrm{NIH}$, National Institute of Environmental Health Sciences (Z01 ES070076 to E M E).

\section{Acknowledgements}

The authors thank Joani Zary-Oswald (ECU) and Linwood Koonce (NIEHS) for technical assistance.

\section{References}

Anderson EL, Baltus AE, Roepers-Gajadien HL, Hassold TJ, de Rooij DG, van Pelt AM \& Page DC 2008 Stra8 and its inducer, retinoic acid, regulate meiotic initiation in both spermatogenesis and oogenesis in mice. PNAS 105 14976-14980. (doi:10.1073/pnas.0807297105)

Ashby J, Tinwell H \& Haseman J 1999 Lack of effects for low dose levels of bisphenol A and diethylstilbestrol on the prostate gland of CF1 mice exposed in utero. Regulatory Toxicology and Pharmacology 30 156-166. (doi:10.1006/rtph.1999.1317)

Baltus AE, Menke DB, Hu YC, Goodheart ML, Carpenter AE, de Rooij DG \& Page DC 2006 In germ cells of mouse embryonic ovaries, the decision to enter meiosis precedes premeiotic DNA replication. Nature Genetics 38 1430-1434. (doi:10.1038/ng1919)

Bedford JM 2015 The epididymis re-visited: a personal view. Asian Journal of Andrology 17 693-698.

Bellve AR, Cavicchia JC, Millette CF, O'Brien DA, Bhatnagar YM \& Dym M 1977 Spermatogenic cells of the prepuberal mouse. Isolation and morphological characterization. Journal of Cell Biology 74 68-85. (doi:10.1083/jcb.74.1.68)

Berry ML \& Linder CC 2007 Breeding Systems: Considerations, Genetic Fundamentals, Genetic Background, and Strain Types, 2nd edn. Boston, MA, USA: Elsevier.

Busada JT \& Geyer CB 2016 The role of retinoic acid (RA) in spermatogonial differentiation. Biology of Reproduction 94 10. (doi:10.1095/ biolreprod.115.135145)

Busada JT, Kaye EP, Renegar RH \& Geyer CB 2014 Retinoic acid induces multiple hallmarks of the prospermatogonia-to-spermatogonia transition in the neonatal mouse. Biology of Reproduction 90 64. (doi:10.1095/ biolreprod.113.114645)

Busada JT, Chappell VA, Niedenberger BA, Kaye EP, Keiper BD, Hogarth CA \& Geyer CB 2015a Retinoic acid regulates Kit translation during spermatogonial differentiation in the mouse. Developmental Biology 397 140-149. (doi:10.1016/j.ydbio.2014.10.020)

Busada JT, Niedenberger BA, Velte EK, Keiper BD \& Geyer CB 2015b Mammalian target of rapamycin complex 1 (mTORC1) is required for mouse spermatogonial differentiation in vivo. Developmental Biology 407 90-102. (doi:10.1016/j.ydbio.2015.08.004) 
Chappell VA, Busada JT, Keiper BD \& Geyer CB 2013 Translational activation of developmental messenger RNAs during neonatal mouse testis development. Biology of Reproduction 89 61. (doi:10.1095/ biolreprod.113.109819)

Cho C, Willis WD, Goulding EH, Jung-Ha H, Choi YC, Hecht NB \& Eddy EM 2001 Haploinsufficiency of protamine-1 or -2 causes infertility in mice. Nature Genetics 28 82-86. (doi:10.1038/ng0501-82)

Curtis JT 2010 Does fertility trump monogamy? Animal Behaviour 80 319-328. (doi:10.1016/j.anbehav.2010.05.014)

Dohle GR, Smit M \& Weber RF 2003 Androgens and male fertility. World Journal of Urology 21 341-345. (doi:10.1007/s00345-003-0365-9)

Drumond AL, Meistrich ML \& Chiarini-Garcia H 2011 Spermatogonial morphology and kinetics during testis development in mice: a highresolution light microscopy approach. Reproduction 142 145-155. (doi:10.1530/REP-10-0431)

Geserick C, Weiss B, Schleuning WD \& Haendler B 2002 OTEX, an androgen-regulated human member of the paired-like class of homeobox genes. Biochemical Journal 366 367-375. (doi:10.1042/ bj20020399)

Geyer CB \& Eddy EM 2008 Identification and characterization of Rhox13, a novel X-linked mouse homeobox gene. Gene 423 194-200. (doi:10.1016/j.gene.2008.06.031)

Geyer CB, Saba R, Kato Y, Anderson AJ, Chappell VK, Saga Y \& Eddy EM 2012 Rhox13 is translated in premeiotic germ cells in male and female mice and is regulated by NANOS2 in the male. Biology of Reproduction 86 127. (doi:10.1095/biolreprod.111.094938)

Hinton BT, Palladino MA, Rudolph D, Lan ZJ \& Labus JC 1996 The role of the epididymis in the protection of spermatozoa. Current Topics in Developmental Biology 33 61-102. (doi:10.1016/s00702153(08)60337-3)

Huszar JM, Jia Y, Reddy JK \& Payne CJ 2015 Med1 regulates meiotic progression during spermatogenesis in mice. Reproduction 149 597-604. (doi:10.1530/REP-14-0483)

Inselman AL, Nakamura N, Brown PR, Willis WD, \& Goulding EH \& Eddy EM 2010 Heat shock protein 2 promoter drives Cre expression in spermatocytes of transgenic mice. Genesis 48 114-120. (doi:10.1002/ dvg.20588)

Jackson-Grusby L, Beard C, Possemato R, Tudor M, Fambrough D, Csankovszki G, Dausman J, Lee P, Wilson C, Lander E et al. 2001 Loss of genomic methylation causes p53-dependent apoptosis and epigenetic deregulation. Nature Genetics 27 31-39. (doi:10.1038/ 83730)

Jones RC 1999 To store or mature spermatozoa? The primary role of the epididymis. International Journal of Andrology 22 57-67. (doi:10.1046/ j.1365-2605.1999.00151.x)

Joyce KL, Porcelli J Cooke PS 1993 Neonatal goitrogen treatment increases adult testis size and sperm production in the mouse. Journal of Andrology 14 448-455.

Krishnamurthy H, Babu PS, Morales CR \& Sairam MR 2001 Delay in sexual maturity of the follicle-stimulating hormone receptor knockout male mouse. Biology of Reproduction 65 522-531. (doi:10.1095/ biolreprod65.2.522)

MacLean JA 2nd \& Wilkinson MF 2010 The Rhox genes. Reproduction 140 195-213. (doi:10.1530/REP-10-0100)

Maclean JA 2nd, Chen MA, Wayne CM, Bruce SR, Rao M, Meistrich ML, Macleod C \& Wilkinson MF 2005 Rhox: a new homeobox gene cluster. Cell 120 369-382. (doi:10.1016/j.cell.2004.12.022)

MacLean JA 2nd, Lorenzetti D, Hu Z, Salerno WJ, Miller J \& Wilkinson MF 2006 Rhox homeobox gene cluster: recent duplication of three family members. Genesis 44 122-129. (doi:10.1002/gene.20193)

Maclean JA, Bettegowda A, Kim BJ, Lou CH, Yang SM, Bhardwaj A, Shanker S, Hu Z, Fan Y, Eckardt S et al. 2011 The rhox homeobox gene cluster is imprinted and selectively targeted for regulation by histone h1 and DNA methylation. Molecular Cell Biology 31 1275-1287. (doi:10.1128/MCB.00734-10)
Moore HD 1998 Contribution of epididymal factors to sperm maturation and storage. Andrologia 30 233-239. (doi:10.1111/j.1439-0272.1998. tb01165.x)

Niedenberger BA, Busada JT \& Geyer CB 2015 Marker expression reveals heterogeneity of spermatogonia in the neonatal mouse testis. Reproduction 149 329-338. (doi:10.1530/REP-14-0653)

Niu AL, Wang YQ, Zhang H, Liao CH, Wang JK, Zhang R, Che J \& Su B 2011 Rapid evolution and copy number variation of primate RHOXF2, an X-linked homeobox gene involved in male reproduction and possibly brain function. BMC Evolutionary Biology 11 298. (doi:10.1186/14712148-11-298)

Oda M, Yamagiwa A, Yamamoto S, Nakayama T, Tsumura A, Sasaki H, Nakao K, Li E \& Okano M 2006 DNA methylation regulates long-range gene silencing of an X-linked homeobox gene cluster in a lineagespecific manner. Genes \& Development 20 3382-3394. (doi:10.1101/ gad.1470906)

Richardson ME, Bleiziffer A, Tuttelmann F, Gromoll J \& Wilkinson MF 2014 Epigenetic regulation of the RHOX homeobox gene cluster and its association with human male infertility. Human Molecular Genetics 23 12-23. (doi:10.1093/hmg/ddt392)

Robb GW, Amann RP \& Killian GJ 1978 Daily sperm production and epididymal sperm reserves of pubertal and adult rats. Journal of Reproduction and Fertility 54 103-107. (doi:10.1530/jrf.0.0540103)

Song HW, Anderson RA, Bayne RA, Gromoll J, Shimasaki S, Chang RJ, Parast MM, Laurent LC, de Rooij DG, Hsieh TC et al. 2013 The RHOX homeobox gene cluster is selectively expressed in human oocytes and male germ cells. Human Reproduction 28 1635-1646. (doi:10.1093/ humrep/det043)

Takasaki N, Mclsaac R \& Dean J 2000 Gpbox (Psx2), a homeobox gene preferentially expressed in female germ cells at the onset of sexual dimorphism in mice. Developmental Biology 223 181-193. (doi:10.1006/dbio.2000.9741)

Takasaki N, Rankin T \& Dean J 2001 Normal gonadal development in mice lacking GPBOX, a homeobox protein expressed in germ cells at the onset of sexual dimorphism. Molecular Cell Biology 21 8197-8202. (doi:10.1128/mcb.21.23.8197-8202.2001)

Wang X \& Zhang J 2006 Remarkable expansions of an X-linked reproductive homeobox gene cluster in rodent evolution. Genomics $\mathbf{8 8}$ 34-43. (doi:10.1016/j.ygeno.2006.02.007)

Wayne CM, MacLean JA, Cornwall G \& Wilkinson MF 2002 Two novel human X-linked homeobox genes, hPEPP1 and hPEPP2, selectively expressed in the testis. Gene 301 1-11. (doi:10.1016/S03781119(02)01087-9)

Welborn JP, Davis MG, Ebers SD, Stodden GR, Hayashi K, Cheatwood JL, Rao MK \& MacLean JA 2nd 2015 Rhox8 ablation in the sertoli cells using a tissue-specific RNAi approach results in impaired male fertility in mice. Biology of Reproduction 93 8. (doi:10.1095/biolreprod.114.124834)

Wilming LG, Boychenko V Harrow JL 2015 Comprehensive comparative homeobox gene annotation in human and mouse. Database 2015. pii bav091. (doi:10.1093/database/bav091)

Yang QE \& Oatley JM 2014 Spermatogonial stem cell functions in physiological and pathological conditions. Current Topics in Developmental Biology 107 235-267. (doi:10.1016/b978-0-12-4160224.00009-3)

Yoshida S, Sukeno M, Nakagawa T, Ohbo K, Nagamatsu G, Suda T \& Nabeshima Y 2006 The first round of mouse spermatogenesis is a distinctive program that lacks the self-renewing spermatogonia stage. Development 133 1495-1505. (doi:10.1242/dev.02316)

Received 11 May 2016

First decision 30 June 2016

Revised manuscript received 19 July 2016

Accepted 1 August 2016 